\title{
Comparative Study of Family Pathology Based On Old-Age Habitants \& Family Habitants
}

\author{
Himani Bhasin ${ }^{1 *}$
}

Keywords: Family, Old Age, Habitants

The family is a primary social unit of every culture. In India, the family rather as an individual has been considered as the unit of social system. A family is a set of human beings related to each other in a non-professional manner, giving rise to a concrete cohesion within the family. Love, care, and affection are the most prominent human values, which are responsible for maintaining these bonds of relationships within a family. The Indian family reflects the socio-cultural fabric of Indian society, its philosophy and values. (Sethi, 1989)

The relationships within a family are complex of varying degrees of intensity and myriad in nature. The emotional tone, which governs the relationship between any two persons, is continuously influenced in its course by emotional relationships of all others in the family.

This changing manifolds emotional currents and cross currents which determines the prevailing atmosphere in the family which sets the basis for interaction and interpersonal relationship in the family. Family cohesion is defined as the "emotional bonding that family members have toward one another" (Olson, Russell, and Sprengkle 1984, 60). Specific indicators for measuring the family cohesion dimension are emotional bonding, boundaries, coalitions, time, space, friends, decision-making, and interests and recreation.

Over the centuries, the many social changes that have occurred in societies have in one way or the other affected these interactions, despite these changes the family has retained its unity and identity more or less in the same manner as in the past with very little change.

In India, even today, the influence of the family on an individual's life is very high in that there is still relatively lesser scope for individual decision-making Vis -a-Vis family decision making.

\footnotetext{
${ }^{1}$ HR Professional, Pepsi Franchisee, Varun Beverages Limited, Gurgaon, New Delhi, India *Responding Author

(C) 2016, H Bhasin; licensee IJIP. This is an Open Access Research distributed under the terms of the Creative Commons Attribution License (http://creativecommons.org/licenses/by/2.0), which permits unrestricted use, distribution, and reproduction in any Medium, provided the original work is properly cited.
} 


\section{Comparative Study of Family Pathology Based On Old-Age Habitants \& Family Habitants}

The interactions continue to be relatively more one side viz. parent to the child, the husband to the wife and the grandparents to the parent. This could be seen in many families, where one finds practically an inflexible interaction of a one sided nature.

In the western families, while the children become independent of the parents by the time they finish school in India, the dependence of an individual on his family continues on. While the core relationship in the western families hinges between the husband and the wife, in India it rests between the parent and the child.

Over the past two decades, a growing body of systems-based research has shown that family processes matter more than family form for healthy individual and family functioning. A number of pioneering assessment models have advanced our knowledge of multidimensional processes that distinguish well-functioning from dysfunctional families (Beavers \& Hampson, 1990) .Despite some differences in constructs and methodology, there is remarkable consistency in findings across studies that such interactional processes as cohesion, flexibility, open communication, and problem-solving skills are essential in facilitating basic family functioning and the well-being of members (Walsh, 1993).

\section{REVIEW OF LITERATURE}

A research was conducted to study demographic changes affecting family structure and documentation of the negative effects of care giving have resulted in reservations about its continued prevalence. This study used interview data from 597 families in which the impaired elder resided with and was cared for by household kin. Findings indicated that care giving occurred in diverse household configurations involving a substantial proportion of male caregivers, employed caregivers, and multi-generational contexts. Despite the diversity, most caregivers indicated a permanent commitment to the role. Although each day they provided on average three hours of personal care alone, wide variation was found in the incidence and severity of stress effects. Informal and formal supports, though present, seemed to supply relatively little hands-on care.(Linda. S. \& Robert. W. Wallace, 1972)

The gendered nature of elder abuse and its relationship to oppression based on race are important areas that have been eclipsed by current policy objectives. In conclusion, a way forward is suggested concerning the future direction of social policy in this area. (B.Simon, 1982)

Life-long instances of family pathology which continue in the patient's adult life present us with unique opportunities in which to attempt to understand the developmental origins of such an individual's adult personality disturbance. It is with such cases that the so-called infantile neurosis - at least in its general structural, genetic, and dynamic outlines-appears to have had a considerable restructuring influence in the formation of the adult neurosis. Since the pathological family milieu in such instances has succeeded in providing a certain 'critical state' for the 


\section{Comparative Study of Family Pathology Based On Old-Age Habitants \& Family Habitants}

maintaining of the childhood in adulthood, it has been in effect a major inhibiting force in the failure for resolving much of the pathology.(C.Roy,T.M.Alston,1989)

Although specific typologies, classifications, or taxonomies of family pathology have been demonstrated to have research merit, it is clear that their practical or clinical application has been at best marginal. The general theories in family therapy have not yet led to the development of viable typologies.

\section{METHODOLOGY}

\section{Sample size:}

30 individuals ranged between 60-70 years of age.

15 individuals from Metropolitan city- Delhi

15 individuals from old-age home- Earth Savior Foundation, Vasant Kunj, Delhi

\section{Variables:}

Independent Variable- Individuals staying in old-age homes\&normal scenario Dependent Variable- Family pathology of individuals staying in old-age homes \& normal scenario

\section{Psychological tools used:}

\begin{tabular}{|l|l|l|l|}
\hline Sno: & Name of the Tool & Developed by & Year \\
\hline 1$)$ & $\begin{array}{l}\text { FAMILY } \\
\text { PATHOLOGY } \\
\text { SCALE }\end{array}$ & $\begin{array}{l}\text { Dr.Vimala Veeraraghavan } \\
\text { Dr. Archana Dogra }\end{array}$ & 1999 \\
\hline
\end{tabular}

\section{RESULTS}

As assessed under the Family Pathology Study, amongst the old-age habitants, there were 8 individuals showing low pathology. This indicates that these individuals have an unstable family environment \& poor emotional stability with their family members whereas, 7 individuals showed moderate family pathology. This shows that these individuals have a stable family environment \& good emotional stability.

Moreover, amongst the normal scenario, there were 8 individuals showing high family pathology. This indicates that these individuals have a very stable family environment \& good emotional stability whereas, 7 individuals exhibited moderate family pathology. This shows that these individuals have a stable family environment.

Also, the standard deviation for the group of old-age habitants came out to be 10.85 and for normal scenario, the standard deviation came out to be 16.45 . 


\section{Comparative Study of Family Pathology Based On Old-Age Habitants \& Family Habitants}

The T-test scores for the group of old-age habitants and normal scenario came out to be 9.27. The given table represents the low, moderate \& high family pathology division amongst the normal scenario \& the old-age habitants:-

Table 1-

\begin{tabular}{|l|l|l|}
\hline Sno: & $\begin{array}{l}\text { FAMILY } \\
\text { PATHOLOGY } \\
\text { DIVISION }\end{array}$ & $\begin{array}{l}\text { DIVISION OF UNITS AMONGST THE OLD AGE } \\
\text { HABITANTS }\end{array}$ \\
\hline 1 & LOW & 8 \\
\hline 2 & MODERATE & 7 \\
\hline 3 & HIGH & 0 \\
\hline
\end{tabular}

Table 2-

\begin{tabular}{|l|l|l|}
\hline Sno: & $\begin{array}{l}\text { FAMILY } \\
\text { PATHOLOGY } \\
\text { DIVISION }\end{array}$ & $\begin{array}{l}\text { DIVISION OF UNITS AMONGST THE NORMAL } \\
\text { SCENARIO }\end{array}$ \\
\hline 1 & LOW & 0 \\
\hline 2 & MODERATE & 7 \\
\hline 3 & HIGH & 8 \\
\hline
\end{tabular}

The table 1 \& table 2 show inferential statistics. A questionnaire was distributed to 15 old age habitants and normal scenario people to assess the family pathology between the two groups. The frequency represents the individuals who fall under low, moderate or high family pathology respectively.

Statistical Analysis:-

\begin{tabular}{|l|l|l|c|}
\hline Groups & $\begin{array}{l}\text { Mean } \\
(\mathrm{N}=15)\end{array}$ & Standard Deviation & T-test \\
\hline $\begin{array}{l}\text { 1) Family } \\
\text { habitants }\end{array}$ & 93.3 & 10.85 & 9.27 \\
\hline $\begin{array}{l}\text { 2) Old-age } \\
\text { habitants }\end{array}$ & 59.9 & 16.45 & 9.27 \\
\hline
\end{tabular}

The table 3 shows descriptive statistics. The T- test was used to assess the difference of means of the two groups i.e. old age habitants \& normal scenario people. The T test came out to be $9.27 \&$ there has been no significant difference between the two groups.

$\mathrm{t}>$ at $0.05^{*}$ level

$\mathrm{t}>$ at $0.01^{*}$ level

(c) The International Journal of Indian Psychology, ISSN 2348-5396 (e)| ISSN: 2349-3429 (p) | 144 


\section{Comparative Study of Family Pathology Based On Old-Age Habitants \& Family Habitants}

\section{DISCUSSIONS}

Family pathology refers to how a family functions as a unit and to the dynamics between the individual family members. It also includes behaviors such as family violence, sexual abuse, and incest and other aberrant behaviors, drugs, etc.

According to the comparative study conducted under the Family Pathology Scale, it has been observed that most old-age habitants have a low family pathology as compared to moderate or high family pathology. This shows that these individuals have an unstable family environment. Moreover, a research which exhibits the importance of family pathology \& the individual pathology is as follows-

Interpersonal pathology of the family was defined in a way that was conceptually distinct from the pathology of its individual members. Three manifestations of family pathology-intermember conflict, low solidarity, and member dissatisfaction - were found to co vary in three different samples of 96, 46, and 50 "normal-range” families, containing a total of 724 responding members.

Three aspects of individual pathology-neurotic symptoms, low self-esteem, and dissatisfaction with life circumstances - were also found to co vary over individuals in each of the three samples. Members of the same family tended to display similar levels of individual pathology. Henceforth, most elders staying in the old-age homes have a low family pathology. Moreover, they are at higher risk of Psychiatric disorders such as depression, anxiety, stress, heart-related problems.

They might exhibit symptoms of aloofness, dependence, loneliness, lack of emotional support etc.

The behaviors exhibited by individuals showing low family pathology are as follows:-

1- $\quad$ Absence of involvement

2- $\quad$ Involvement devoid of feelings

3- Narcissist involvement

4- Over involvement

5- $\quad$ Empathetic involvement

6- $\quad$ Meeting \& expressing psychobiological needs (sleeping, eating, drinking)

7- $\quad$ Restlessness

8- $\quad$ Crying spells

In the normal scenario, most individuals exhibited high family pathology. This indicates that these individuals have a very stable family environment. 


\section{Comparative Study of Family Pathology Based On Old-Age Habitants \& Family Habitants}

\section{CONCLUSION}

According to the comparative study conducted under the Family Pathology Scale, it has been observed that most old-age habitants have a low family pathology as compared to moderate or high family pathology. This shows that these individuals have an unstable family environment. In the normal scenario, most individuals exhibited high family pathology. This indicates that these individuals have a very stable family environment. Moreover, these individuals also have good emotional stability with their family members \& friendly relations with their family members. They also exhibit strong emotional bonding with their family members \& an affectionate relation of love, intimacy, care, concern. This results in lack of domestic violence in the family \& less chance of domestic abuse in the family.

\section{Acknowledgments}

The author appreciates all those who participated in the study and helped to facilitate the research process.

\section{Conflict of Interests}

The author declared no conflict of interests.

\section{REFERENCES}

B. Simon. Family Pathology \& elder Abuse. New Jersey, USA (1982)

C.Roy TM Alston, Family Pathology \& Personality disturbances, India (1989)

Lawrence, George N. Family pathology (fourth edition), New York: Academic Press (1993)

Noelkar, LS Interpersonal relationships in a family, Journal of Family Issues, New York (1985)

Parsons, Bales. Family functioning \& Pathology. United Kingdom (1963)

Rothstein, William G. "Pathology : The concept of family resilience” Chicago (1979)

S. William S. Ruth. Interpersonal Pathology of the family. United Kingdom (1975)

T. Lenore. Family Pathology \& Post Traumatic effects. China (1983)

\section{Web References}

- www.agingresources.com/

- www.apa.org

- www.health.gov

- link.springer.com

- www.ncbi.nlm.nih.gov

- www.treasury.govt.nz/publications/research-policy

- www.uptodate.com/contents/frontotemporal-dementia-epidemiology-pathology-andpathogenesis/abstract/3-

- www.stat.washington.edu|

How to cite this article: H Bhasin (2016), Comparative Study of Family Pathology Based On Old-Age Habitants \& Family Habitants, International Journal of Indian Psychology, Volume 3, Issue 4, No. 67, ISSN:2348-5396 (e), ISSN:2349-3429 (p), DIP:18.01.189/20160304, ISBN:9781-365-39397-6

(C) The International Journal of Indian Psychology, ISSN 2348-5396 (e)| ISSN: 2349-3429 (p) | 146 